\title{
Design and analysis of buoy geometries for a wave energy converter
}

\author{
Pedro Jorge Borges Fontes Negrão Beirão • \\ Cândida Maria dos Santos Pereira Malça
}

Received: 8 October 2013/Accepted: 13 March 2014/Published online: 1 May 2014

(c) The Author(s) 2014. This article is published with open access at Springerlink.com

\begin{abstract}
This paper describes the design and analysis of several buoy geometries that may be applied to a near-shore floating point-absorber wave energy converter. After the characterisation of the device, a numerical model and a simulator in the time domain were developed and the structural performance of the wave energy converter evaluated for three different buoy geometries. The influence of the buoy dimensions, different submerged conditions and position of hydraulic cylinder piston rod, on the structural performance of the wave energy converter is also analysed. The numerical study was conducted using a commercial finite element code. This software needs, among other parameters, the magnitude of the forces acting upon each buoy. A dynamic model was, therefore, developed assuming that the buoy heave motion is excited by the sea waves. The finite element analysis revealed that a load with a higher magnitude than those computed from the simulator was required. It was shown that, even considering the partially submerged condition, the spherical buoy geometry leads to best structural behaviour.
\end{abstract}

Keywords Wave energy converter - Buoy geometries . WEC dynamic model · WEC finite element model

\section{Abbreviations \\ WEC Wave energy converter}

P. J. B. F. N. Beirão (凹) · C. M. dos Santos Pereira Malça Polytechnic Institute of Coimbra, ISEC, DEM, Rua Pedro Nunes, Quinta da Nora, 3030-199 Coimbra, Portugal e-mail: pbeirao@isec.pt

C. M. dos Santos Pereira Malça

e-mail: candida@isec.pt

\section{P. J. B. F. N. Beirão}

LAETA, IDMEC, Instituto Superior Técnico, Universidade

Técnica de Lisboa, Lisboa, Portugal

\begin{tabular}{ll} 
PTO & Power take-off \\
$f_{\text {ext }}$ & Total external force \\
$m_{\mathrm{b}}$ & Buoy mass \\
$\ddot{z}$ & Buoy acceleration \\
$\rho_{\mathrm{b}}$ & Buoy density \\
$V_{\mathrm{b}}$ & Buoy volume \\
$f_{\mathrm{PTO}}$ & PTO force \\
$f_{\mathrm{w}}$ & Wave force \\
$f_{\text {exc }}$ & Heave excitation force \\
$f_{\mathrm{r}}$ & Radiation force \\
$\dot{z}$ & Buoy velocity \\
$z$ & Buoy displacement \\
$m_{\mathrm{a}}$ & Added mass \\
$c$ & Stiffness coefficient \\
$B$ & Radiation damping coefficient \\
$r$ & Radius \\
$\rho_{\mathrm{w}}$ & Seawater density \\
$f_{\mathrm{d}}$ & Damping force \\
$C_{\mathrm{d}}$ & Drag coefficient \\
$A_{\mathrm{proj}}$ & Projected area of the buoy \\
$u$ & Fluid velocity \\
$H$ & Wave height \\
$T$ & Wave period \\
$\lambda$ & Wavelength \\
$\omega$ & Wave angular frequency \\
$f_{\mathrm{b}}$ & Buoyancy force \\
$g$ & Acceleration due to gravity \\
$A$ & Cross-sectional area of the buoy \\
$R$ & Radiation coefficient \\
$\gamma$ & Damping coefficient \\
& \\
\hline
\end{tabular}

Introduction

In the past few decades, world energy consumption grew considerably. With the decay of fossil resources, renewable 
energy sources are facing a growing demand. Among them, ocean wave energy is one of the most promising alternatives regarding the production of electricity [1]. This renewable energy source relies upon a vast energy resource providing a high power density when compared, for instance, with solar and wind energies. Additionally, it is more reliable than most of other renewable energy sources, since wave power availability can surpass 90 percent of the time while solar and wind availability only reach 20-30\% of the time [2]. This allows the high utilisation of wave power plants over the year, as well as their customization through engineering solutions that match those devices to different ocean climates [3].

Although in an early stage of development when compared with more mature renewable energy sources, different countries with exploitable wave power resources started considering wave energy as a possible source of power supply. However, devices suitable to harness this kind of renewable energy source and turn it into electricity are not yet commercially competitive [1] when compared with more mature renewable energies, such as wind and solar. Currently, there are numerous concepts of wave energy converters (WEC) being developed and tested around the world which require a great deal of investigation. Some of them have been already submitted to real ocean conditions and a few full-scale devices have been operating under a more or less continuous basis [4].

The general WEC architecture is depicted in Fig. 1 [5]. This small-scaled near-shore WEC belongs to the point absorber category [6], since its characteristic dimension has a negligible size when compared to the ocean wavelength. The two main components are buoy, which floats with the sea waves, connected to a double effect hydraulic cylinder by supporting cables. Although six modes of motion are possible [6], the floating buoy is assumed to oscillate only in heave mode. The working principle will be explained in the next section.

To convert the energy available from the ocean waves into electricity, WECs must have some kind of mechanism by which energy is transferred between the waves and the device itself [7]. This is generally known as the power takeoff (PTO). The main characteristics of a PTO system should include, among others: the ability to create high thrust since sea waves produce slow velocities upon the floating bodies; high efficiency which is related from the economical point of view with the electricity cost; low maintenance requirements due to the WEC inaccessibility during large periods of time [8]. Being a near-shore WEC, the PTO components should be enclosed in a sealed waterproof concrete mooring foundation placed at the seabed.

The extraction of energy from ocean waves requires at least that the waves exert force upon some form of resistive mechanism and also some kind of reference against which

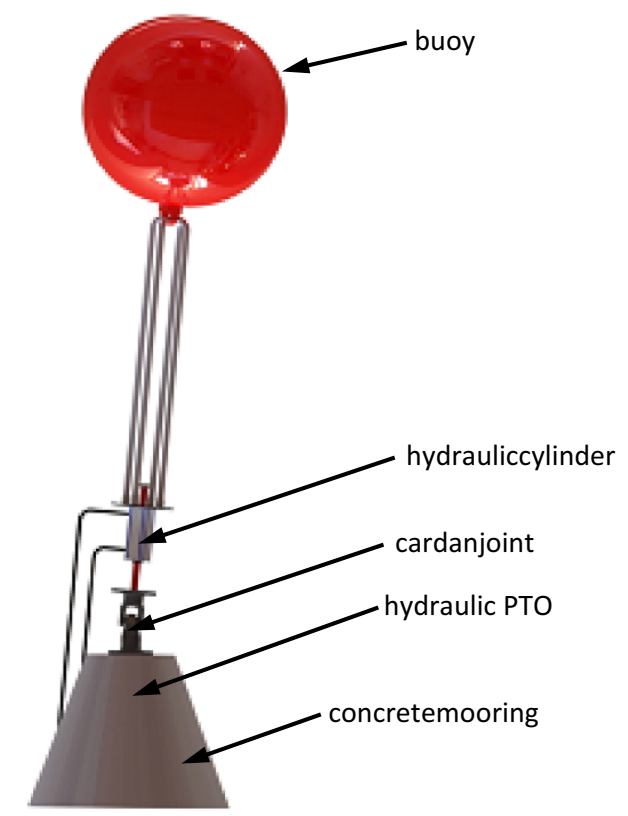

Fig. 1 WEC design

that mechanism can react [7]. The foundations provide that reaction force [5].

The initial section of this paper describes a simple and affordable floating point-absorber WEC equipped with a hydraulic PTO. More information about this subject can be found in [5]. The following section refers to the design and analysis, from a structural point of view, of several buoy geometries. It includes the derivation of equations for the forces considered as inputs in a commercial finite element code. Results are presented in an independent section. The last section draws the principal conclusions.

\section{WEC characterisation}

The working principle is quite simple. When submitted to the sea waves the buoy floats and moving upwards under the influence of a wave crest and moves downwards under the effect of a wave trough. The buoy is connected to a double effect hydraulic cylinder by supporting cables. A cardan joint connects the piston rod of the hydraulic cylinder to the concrete mooring.

The relative heave motion between those two main components will be converted into electrical energy by means of a PTO [9]. The PTO design is based in a hydraulic circuit, schematised in Fig. 2. Many WECs have incorporated hydraulic PTOs in their design [7], since it has several favourable characteristics, being an affordable, robust and well-proven technology [10]. Sea waves induce large forces at low velocity movements making hydraulic PTOs suited to absorbing energy under this condition [7]. The hydraulic design also produces a smooth output power 


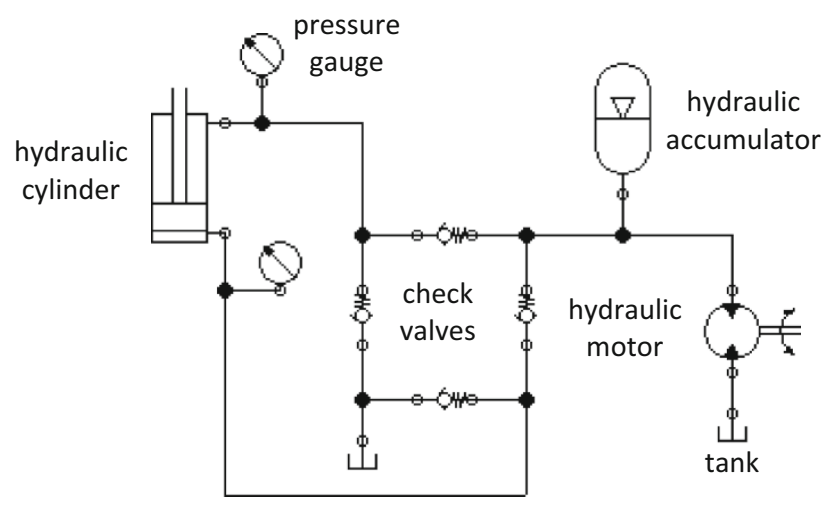

Fig. 2 PTO hydraulic circuit

and is dimensionally compact [6]. Additionally, oil protects the sensitive sliding surfaces from corrosion and lubricates the seals. Nevertheless, there are some disadvantages, since oil spillage is a potential sea pollutant. Also the finite life of seals due to friction and fatigue loading of main components should be taken into account [6]. For a detailed description of a hydraulic PTO see [8], [9].

Apart from the double effect hydraulic cylinder, the other hydraulic PTO components are four non-returnable valves, an oil tank, a hydraulic accumulator and a hydraulic motor mechanically coupled to an electric generator. The hydraulic cylinder will be responsible for the relative motion between the buoy and the mooring platform, but only when the forces applied to the buoy surpass the hydraulic force corresponding to the pressure difference between the hydraulic accumulator and the tank. The maximum velocity allowed for hydraulic cylinders is $0.5 \mathrm{~m} / \mathrm{s}$, however, a velocity of $0.1 \mathrm{~m} / \mathrm{s}$ should be used to extend the life of the hydraulic cylinder seals [8].

As stated above, the successive wave crests and troughs cause the heave motion of the buoy connected to the hydraulic cylinder. To harness energy from the motion of the buoy the system should provide a reaction force at the hydraulic cylinder. As a matter of fact the force developed by the buoy is transmitted through the PTO system. As a consequence the hydraulic cylinder pumps oil from the tank to the hydraulic accumulator and the fluid returns to the tank through the hydraulic motor. The alternating oil flow is rectified by the non-returnable valves and is smoothed by the hydraulic accumulator [9] which could also be used as energy storage [8]. Since sea waves are irregular, significant variations can occur and the hydraulic accumulator should have enough capacity to accommodate the fluid flow for two or three wave cycles [8]. The goal is to deliver a reasonable smooth electrical output. The continuous flow of the oil through the hydraulic motor is converted in rotational motion [10] and will drive an electric generator, turning at typically 1,000 or $1,500 \mathrm{rpm}$
[6, 9], which will be responsible to convert the wave energy into electricity [9]. There are several options to maintain a continuous rotation of the electrical generator [8]. One is the utilisation of a fixed displacement hydraulic motor, such as a gear motor, to drive a variable speed electrical generator. Another possibility is the utilisation of a hydraulic motor with variable displacement, such as an axial-piston bent-axis motor [9], which would allow a flow rate adjustment according to the average power delivered by the sea waves.

\section{WEC dynamic model}

The dynamic modelling of the WEC describes the buoy heave motion with respect to its acceleration and is based on the second Newton's law.

It is assumed that wave amplitudes and oscillations are sufficiently small when compared with the wavelength. Hence, linear wave theory is used to describe the hydrodynamic behaviour [6] and [11]. The vertical components of the total external force $f_{\text {ext }}$ acting on the buoy results from the sum of several components:

$\sum f_{\mathrm{ext}}=m_{\mathrm{b}} \ddot{z}$

where $m_{\mathrm{b}}$ and $\ddot{z}$ are, respectively, the buoy mass and its corresponding vertical acceleration component. For a spherical buoy of radius $r$ its mass $m_{\mathrm{b}}$ is given by:

$m_{\mathrm{b}}=\rho_{\mathrm{b}} V_{\mathrm{b}} \Leftrightarrow m_{\mathrm{b}}=\rho_{\mathrm{b}} \frac{4}{3} \pi r^{3}$

where $\rho_{\mathrm{b}}$ is the buoy density (given in Table 1 ) and $V_{\mathrm{b}}$ is the buoy volume.

In Eq. (1) $f_{\text {ext }}$ includes the vertical components of the PTO force $f_{\text {PTO }}$ and the wave force $f_{\mathrm{w}}$ which may be decomposed into two hydrodynamic components acting upon the wetted buoy surface. The heave excitation force $f_{\text {exc }}$ due to the incident waves acts upon the assumed stationary buoy and the radiation force $f_{\mathrm{r}}$ due to the energy transfer from the heaving buoy to the waves that are radiated away from the buoy. Hence a possible solution for Eq. (1) is:

$$
\begin{aligned}
\left(m_{\mathrm{b}}+m_{\mathrm{a}}\right) \ddot{z}+B \dot{z}+C z & =f_{\mathrm{w}}+f_{\mathrm{PTO}} \\
& \Leftrightarrow\left(m_{\mathrm{b}}+m_{\mathrm{a}}\right) \ddot{z}+B \dot{z}+C z \\
& =\left(f_{\mathrm{exc}}+f_{\mathrm{r}}\right)+f_{\mathrm{PTO}}
\end{aligned}
$$

where $\dot{z}$ and $z$ are, respectively, the buoy velocity and displacement, $m_{\mathrm{a}}$ is the added mass hydrodynamic coefficient (accounting for the inertia of a given water volume that surrounds the buoy when it heaves [9]), $B$ is the radiation damping coefficient (accounting for the buoy damping due to the transfer of energy to the waves radiated away from the buoy when it heaves [9]). Usually, the frequency-dependent hydrodynamic coefficients may be 
Table 1 Buoy material properties

\begin{tabular}{llllr}
\hline & $\begin{array}{l}\text { Young } \\
\text { modulus } \\
\left(\mathrm{N} / \mathrm{m}^{2}\right)\end{array}$ & $\begin{array}{l}\text { Poisson } \\
\text { coefficient }\end{array}$ & $\begin{array}{l}\text { Yield } \\
\text { strength } \\
\left(\mathrm{N} / \mathrm{m}^{2}\right)\end{array}$ & $\begin{array}{l}\text { Density } \\
\left(\mathrm{kg} / \mathrm{m}^{3}\right)\end{array}$ \\
\hline Polyethylene & $186 \times 10^{7}$ & 0.39 & $30 \times 10^{6}$ & 940 \\
$\begin{array}{l}\text { Polyurethane } \\
\text { AISI 316 } \\
\text { stainless } \\
\text { steel }\end{array}$ & $193 \times 10^{7}$ & 0.39 & $40 \times 10^{6}$ & 45 \\
\hline
\end{tabular}

determined theoretically or computed with the aid of specific software [11, 12]. $C$ is the restoring or stiffness coefficient (accounting for the instantaneous buoy position with respect to the undisturbed free surface [9]). After finding the above coefficients, a time domain solution of the buoy motion can be obtained [12].

According to [13], for a spherical buoy of radius $r$ the added mass $m_{\mathrm{a}}$ may be given by:

$m_{\mathrm{a}}=\frac{1}{2} \rho_{w} V_{\mathrm{b}} \Leftrightarrow m_{\mathrm{a}}=\frac{1}{2} \rho_{\mathrm{w}} \frac{4}{3} \pi r^{3} \Leftrightarrow m_{\mathrm{a}}=\frac{2}{3} \rho_{\mathrm{w}} \pi r^{3}$

where $\rho_{\mathrm{w}}$ is the seawater density.

In Eq. (3) if $B$ is considered as a linear damping coefficient, $B \dot{z}$ corresponds to the damping force $f_{\mathrm{d}}$ that, according to [14] and resorting to the Morison equation [15], may be given by:

$f_{\mathrm{d}}=B \dot{z} \Leftrightarrow f_{\mathrm{d}}=\frac{1}{2} C_{\mathrm{d}} \rho_{\mathrm{w}} A_{\text {proj }} u^{2}$

where $C_{\mathrm{d}}$ is the drag coefficient, $A_{\text {proj }}$ is the buoy projected area normal to the flow and $u$ is the undisturbed fluid velocity relative to the buoy given by [15]:

$u=\frac{\pi H}{T} e^{\left(\frac{2 \pi z}{i}\right)} \cos (\omega t)$

where $H$ is the wave height, $T$ is the wave period, $\lambda$ is the wavelength and $\omega$ is the wave angular frequency.

In Eq. (3) if $C$ is considered a linear restoring or stiffness coefficient, $C z$ corresponds to the hydrostatic buoyancy (restoring or stiffness) force $f_{\mathrm{b}}$ exerted on the buoy due to the instantaneous buoy position with respect to the seawater free surface. It may be given by:

$f_{\mathrm{b}}=C z \Leftrightarrow f_{\mathrm{b}}=\rho_{\mathrm{w}} g A z$

where $g$ is the acceleration due to gravity and $A$ is the buoy cross-sectional area.

In Eq. (3) the radiation force $f_{\mathrm{r}}$ can be derived following [11]. It is assumed that the buoy behaves like a semi-submerged sphere of radius $r$ on water of infinite depth. Actually, $f_{\mathrm{r}}$ is a damping force which can be given by:

$f_{\mathrm{r}}=-R \dot{z}$

where $R$ is the radiation coefficient.
In Eq. (3) the heave excitation force $f_{\text {exc }}$ can be obtained based on [6] and [14]. For simplicity reasons, only sinusoidal or monochromatic regular waves were considered. As a consequence $f_{\text {exc }}$ will be given by:

$f_{\text {exc }}=\left|f_{\text {exc }}\right| \cos (\omega t)$

where the amplitude of the heave excitation force $\left|f_{\text {exc }}\right|$ can be computed from [11] and [16].

In Eq. (3) the PTO force $f_{\text {PTO }}$ can be derived following [17]. This force counteracts the buoy heave motion and it is therefore proportional to the buoy velocity.

$f_{\mathrm{PTO}}=-\gamma \dot{z}$

where $\gamma$ is a damping coefficient.

A simulator of the WEC in the time domain was developed using the Simulink of the Matlab software. The objective is to simulate the dynamic behaviour of the WEC due to the action of sea waves. All the force equations derived above were grouped under individual subsystems, as shown in Fig. 3 [18].

The simulator was used to obtain the magnitude of the total force applied to the external surface of the buoy. This force value was then used as an input in the commercial finite element code.

$500 \mathrm{~s}$ long simulations were carried out using several regular waves with different amplitudes and periods. A $50 \mathrm{~s}$ slice of the evolution of the total force with time is highlighted in Fig. 4 for a wave with amplitude $H$ of $0.7 \mathrm{~m}$ and period $T$ of $7.2 \mathrm{~s}$. It was then considered a maximum total force of $800 \mathrm{~N}$.

\section{WEC numerical model}

A numerical study was made to evaluate the influence of geometry and dimensions of each buoy as well as the position of the double effect hydraulic cylinder on the structural behaviour of the conceptualised WEC when submitted to hydrodynamic forces, a numerical study was conducted. Figure 5 illustrates the mesh geometry obtained, using a commercial finite element code, for the three different buoy geometries under study-spherical, cylindrical and tulip. The tulip geometry is a combination between a cone and a cylinder. For better accuracy, a relatively fine mesh of triangular elements was applied for each buoy geometry that was modelled. The selected solid meshes resulted from the meshing sensitivity study previously performed.

Concerning boundary conditions, the inferior half of the cardan joint is rigidly fixed, i.e. constraints of no displacements and rotations are applied to simulate the WEC mooring system at the sea bottom. The resultant hydrodynamic force, determined from the equations derived in the previous section, is applied to each buoy external 


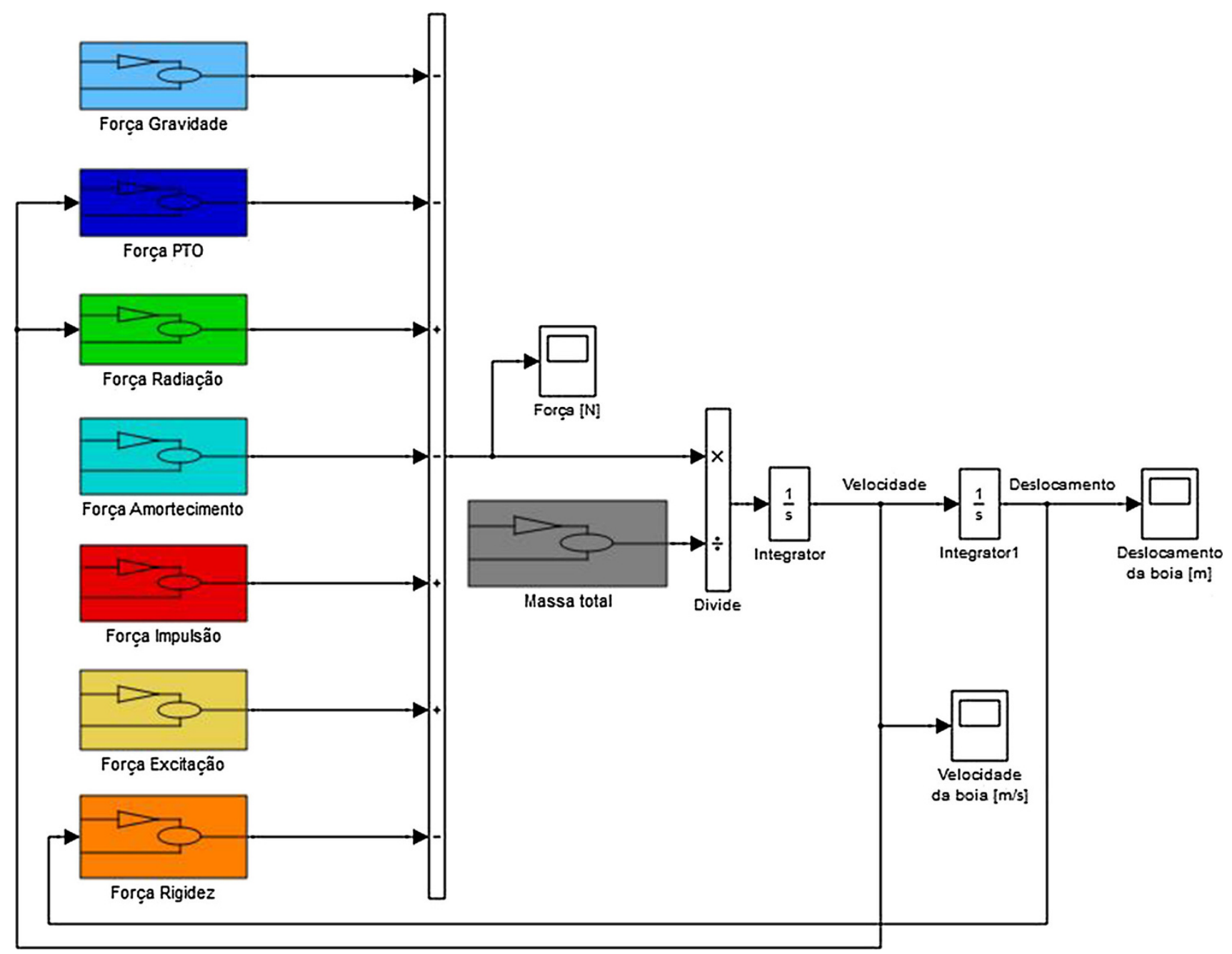

Fig. 3 WEC time domain simulator

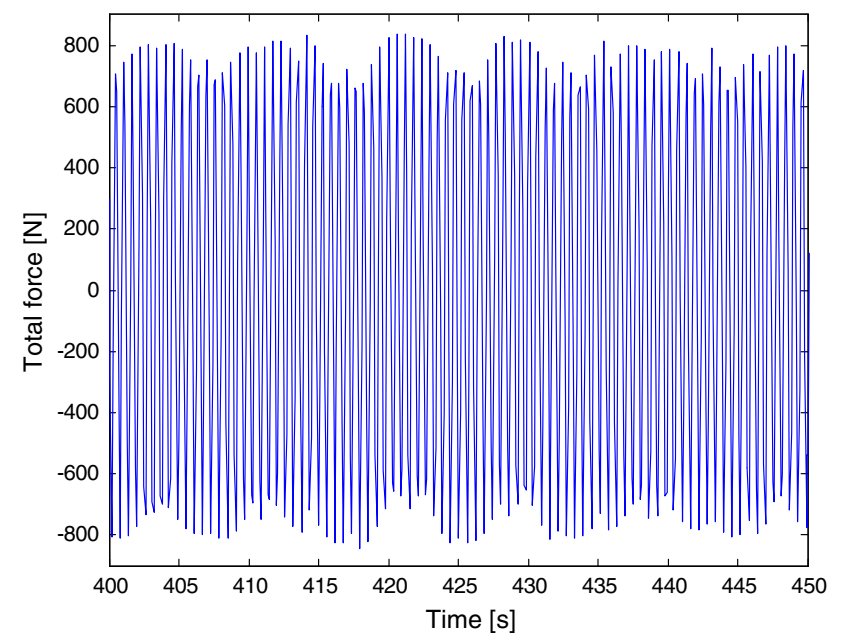

Fig. 4 Evolution of the total force with time for $H=0.7 \mathrm{~m}$ and $T=7.2 \mathrm{~s}$

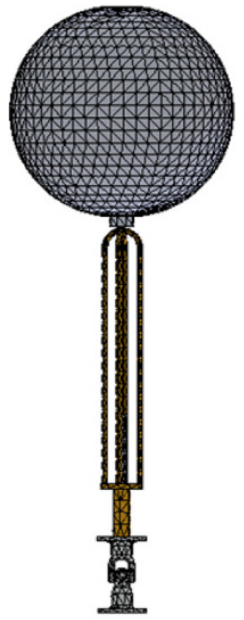

(a)

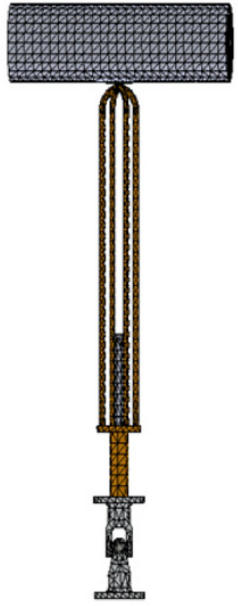

(b)

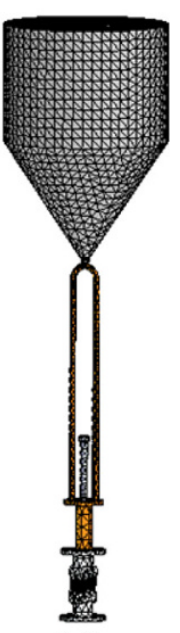

(c)

Fig. 5 Mesh geometry for the three buoy geometries under study: a spherical, b cylindrical and $\mathbf{c}$ tulip 


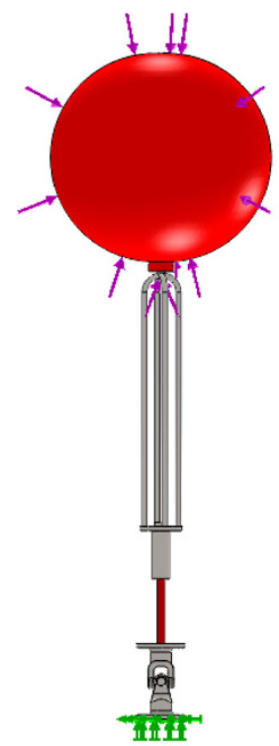

(a)

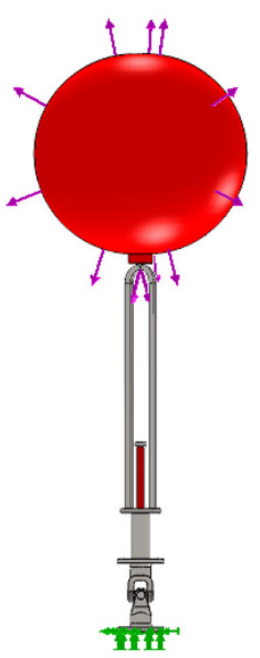

(b)
Fig. 6 Boundary and applied load conditions for two extreme stroke positions of hydraulic cylinder piston rod: a position $A$ and $\mathbf{b}$ position $B$

surface. Figure 6 illustrates, for the spherical buoy geometry, both the boundary conditions and the applied load for situations corresponding to the wave crest and to the wave through. For these two situations, the hydraulic cylinder piston rod assumes extreme stroke positions-position A and position $\mathrm{B}$-corresponding to the fully advanced and retracted positions of the hydraulic cylinder piston rod, respectively.

Except for the buoys, it was considered that all components of the WEC are made of AISI 316 stainless steel. Values for the Young modulus, Poisson coefficient and yield strength are given in Table 1. As regards buoy elastic material properties, most of the buoys commercially available have a polyurethane core and a high-density polyethylene shell. Table 1 resumes the relevant elastic material properties of these two materials. To improve security results, polyethylene was chosen to perform numerical analysis since it is characterised by lower mechanical material properties than those presented by polyurethane.

\section{Results and discussion}

To evaluate which of the buoy geometries induces the best WEC structural behaviour, i.e. which buoy leads to the lower level of stresses concentration and displacements, several calculations were done using a commercial finite element code. Issues such as the influence of the extreme stroke positions of the hydraulic cylinder piston rod and buoy dimensions on the WEC structural performance were

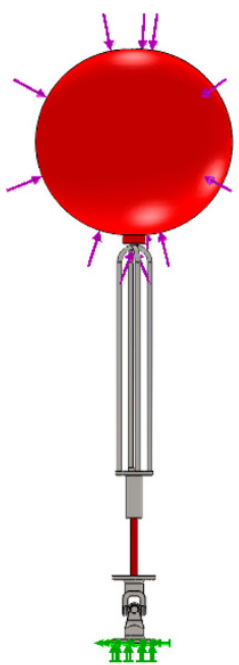

(a)

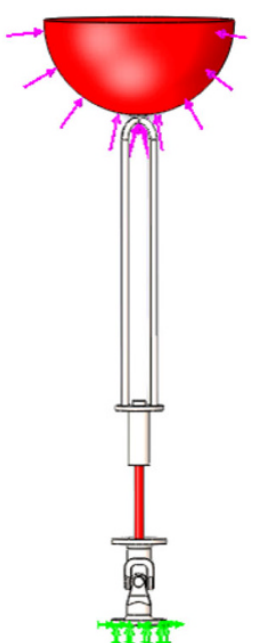

(b)

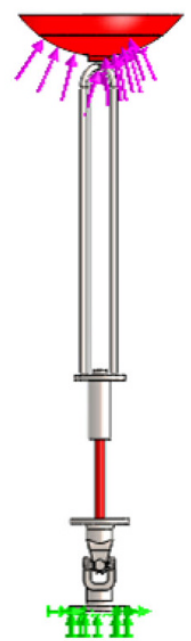

(c)
Fig. 7 Spherical buoy submerged conditions: a totally submerged, b partially submerged and $\mathbf{c}$ at the surface

also analysed. According to the WEC dynamic model it was assumed that the buoys were partially submerged. Additionally, the effects of two other conditions-totally submerged buoy and buoy at the surface-were also evaluated. Figure 7 illustrates, for the spherical buoy geometry, the three submerged conditions that were analysed.

Analysis using the finite element method provides insight into the stress concentrators' magnitude and location. The total force value computed from the equations of the WEC dynamic model was firstly used as inputs in the finite element tool. Results reveal that maximum stresses obtained never exceeded the yield strength of AISI 316 stainless steel. Furthermore, they were extremely low, not allowing any conclusion about the comparison between the behaviour presented by the different buoy geometries. A load of $25 \mathrm{kN}$ was, therefore, applied. Figure 8 shows the Von Mises Stress gradient determined by the analysis for: (a) spherical, (b) cylindrical and (c) tulip buoys partially submerged with radius $100 \mathrm{~mm}$ considering the advanced position of the hydraulic cylinder piston rod. Figure 9 is similar to Fig. 8 but concerns mainly the retracted position. Areas of greatest stress are shown in red. As expected, for the advanced position of the hydraulic cylinder piston rod, the areas of highest stress concentration are located in the piston rod and in the supporting cables while for the retracted position maximum stress is located in the cables. No significant differences are observed between the behaviour presented by spherical and tulip geometries, maximum von Mises stress experienced is around of $100 \times 10^{6} \mathrm{~Pa}$. Since the stainless steel piston rod possesses a yield strength of $172 \times 10^{6} \mathrm{~Pa}$, plastic deformation is 


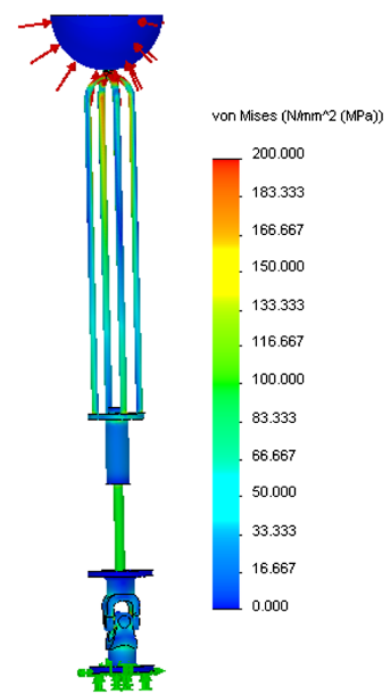

(a)

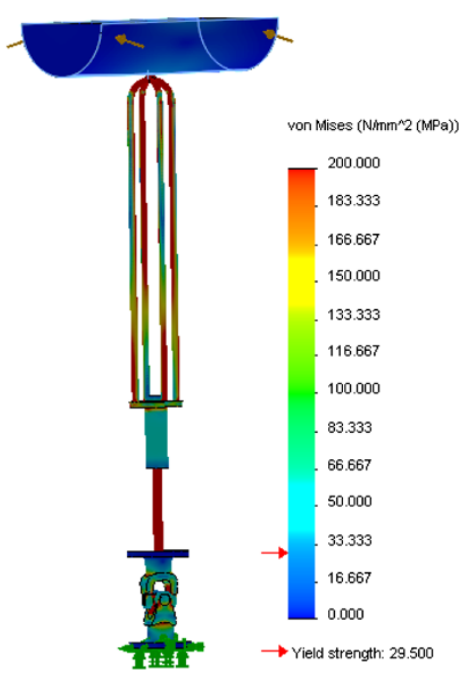

(b)

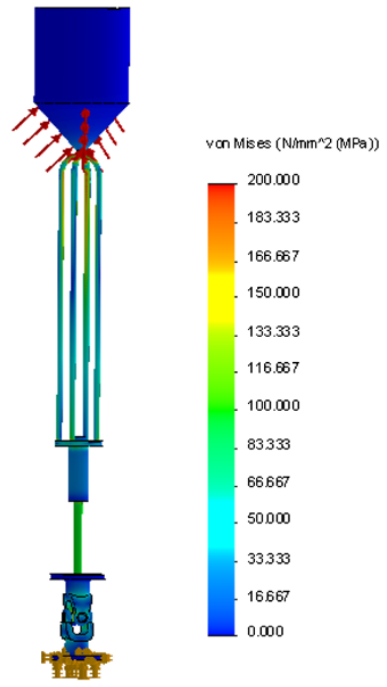

(c)

Fig. 8 Von Mises Stress field for advanced position of the hydraulic cylinder piston rod considering partially submerged buoys with radius $100 \mathrm{~mm}$ : a spherical, b cylindrical and $\mathbf{c}$ tulip

never reached with the level of load applied. For the cylindrical buoy geometry the scenario is quite different. If the advanced position of the hydraulic cylinder piston rod is considered, plastic deformation is reached since maximum stresses are greater than the yield stress of the material of the supporting cables and the piston rod. For the retracted position, maximum stresses occur at the supporting cables. This chaotic situation is confirmed by the higher displacement values that were obtained. Figures 10 and 11 illustrate the displacement gradient determined by the finite element method analysis for: (a) spherical, (b) cylindrical and (c) tulip buoys partially submerged, for the same conditions described in Figs. 8 and 9. The highest magnitude of displacements is obtained, regardless of the buoy geometry, in the buoy and supporting cables. For the spherical and tulip buoy geometries the displacements are acceptable. However, for the cylindrical buoy geometry, values with the same order of magnitude of the component size were obtained. This means that, with the level of load applied and components sizing, the collapse of WEC structure is reached. No noticeable differences are observed between the two extreme stroke positions of the hydraulic cylinder piston rod. From Figs. 8, 9, 10 and 11 it can be concluded that the spherical buoy presents the lower stresses and displacements levels, leading to the best structural behaviour of the WEC.

The influence of different submerged conditions-buoy at the surface and totally submerged buoy-on the structural behaviour of the WEC is displayed, for the spherical buoy geometry, in Figs. 12 and 13, respectively. For the buoy at the surface, regardless of the hydraulic cylinder piston rod position, a considerable decrease in both maximum stresses and displacements values is obtained. This decrease is absolutely remarkable for the totally submerged buoy, where stresses and displacements reach values two orders of magnitude lower. Thus, it can be concluded that the partially submerged buoy corresponds to the critical position. However, this will be the more expected position of the buoy when it heaves due to the action of the sea waves.

Figure 14 shows the consequence on Von Mises Stress and displacement gradients when the radius of the spherical buoy is increased to $200 \mathrm{~mm}$, considering the advanced position of the hydraulic cylinder piston rod and different submerged conditions: (a) and (b) totally submerged buoy, and (c) and (d) partially submerged buoy. For the totally submerged buoy maximum stress values obtained are the lowest ones. In what concerns the displacement field, a slight increase is verified when comparing with the spherical buoy with radius of $100 \mathrm{~mm}$. Regarding the partially submerged buoy, for the level of load applied and for the diameters of the piston rod and supporting cables considered, the increase in the buoy radius led to worrying scenarios. Actually, plastic deformation is reached in most WEC components because maximum stress values largely exceed the yield strength of AISI 316 stainless steel.

From the finite element analysis results and for the sizing WEC components and load level applied it can be concluded that: (1) for the advanced position of the hydraulic cylinder piston rod two critical sections are observed - piston rod and supporting cables, while for the retracted position the highest concentrations are in the supporting cables; (2) the spherical 


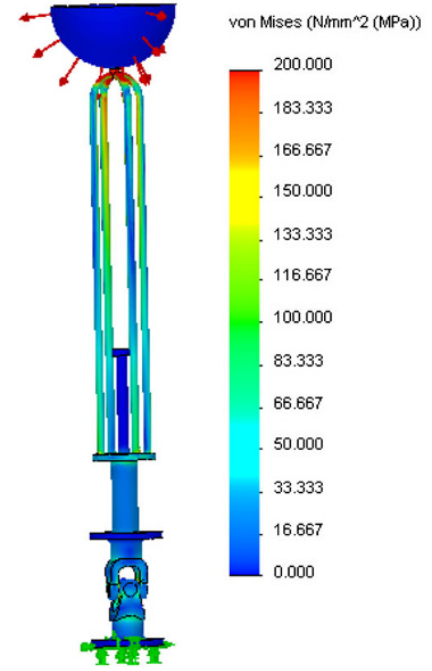

(a)

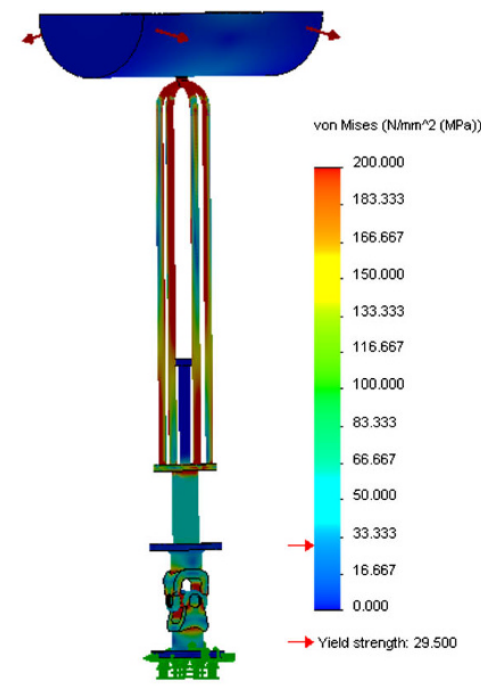

(b)

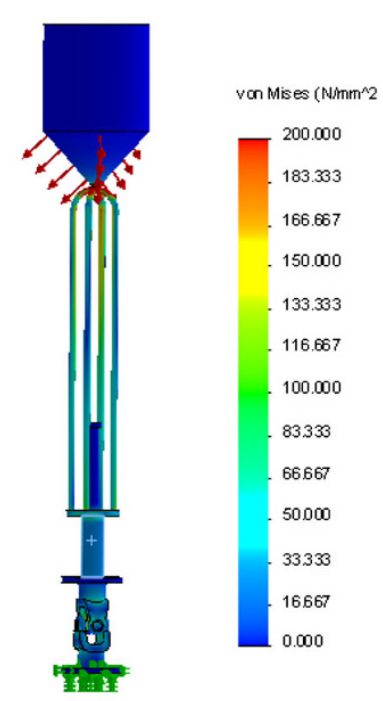

(c)

Fig. 9 Von Mises Stress field for retracted position of the hydraulic cylinder piston rod considering partially submerged buoys with radius $100 \mathrm{~mm}$ : a spherical, b cylindrical and c tulip

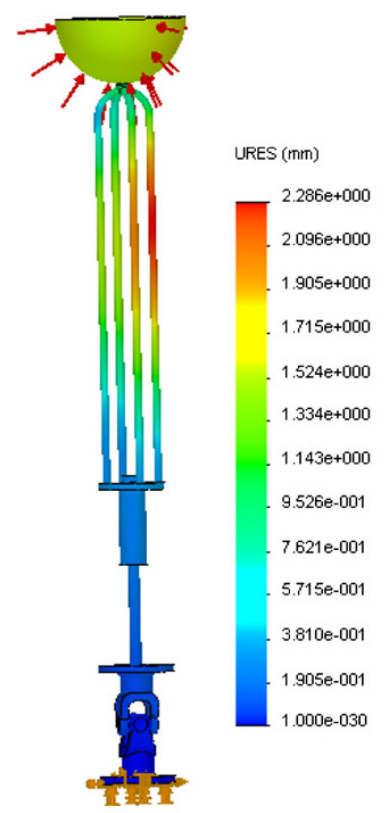

(a)

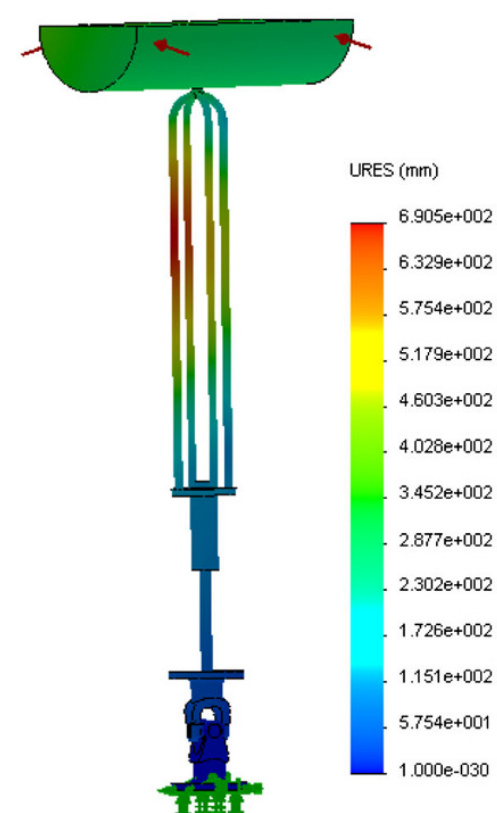

(b)

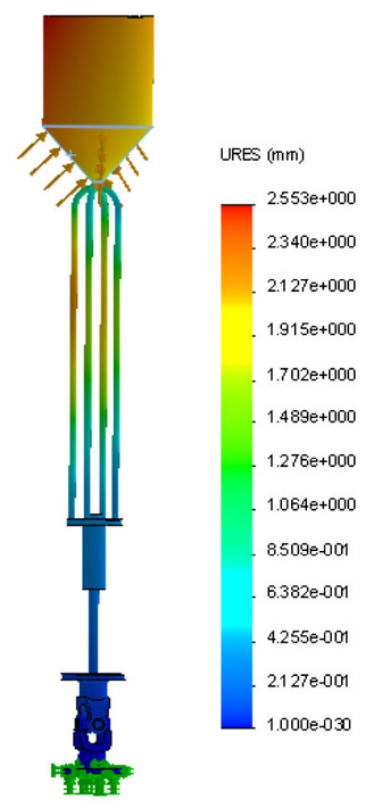

(c)

Fig. 10 Displacement field for advanced position of the hydraulic cylinder piston rod considering partially submerged buoys with radius $100 \mathrm{~mm}$ : a spherical, b cylindrical and $\mathbf{c}$ tulip

buoy with radius of $100 \mathrm{~mm}$ leads to the lowest values of stresses and displacements when compared with the tulip geometry; (3) cylindrical geometry leads to a chaotic scenario due to an extremely high level of stresses and displacements; (4) the partially submerged condition corresponds to the critical buoy position since highest maximum stresses and displacements are reached and (5) the increase in the buoy dimensions leads to plastic deformation of WEC components for the material properties, sizing and load level used in this study.

\section{Conclusions}

The main goal of this work is to provide a deeper understanding of the WEC structural performance when 


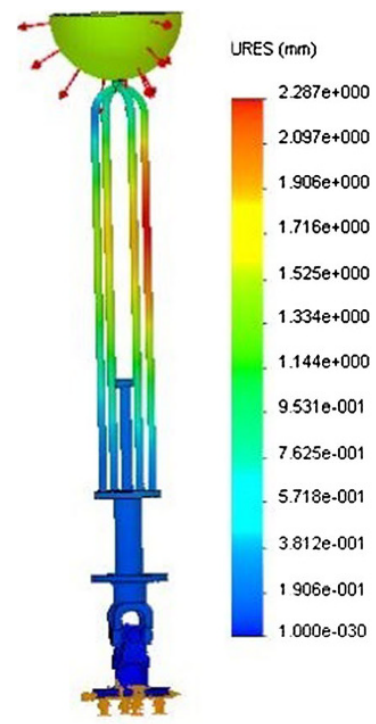

(a)

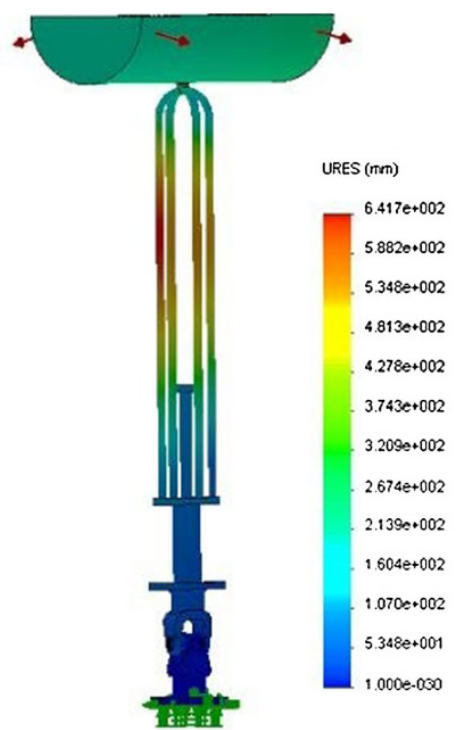

(b)

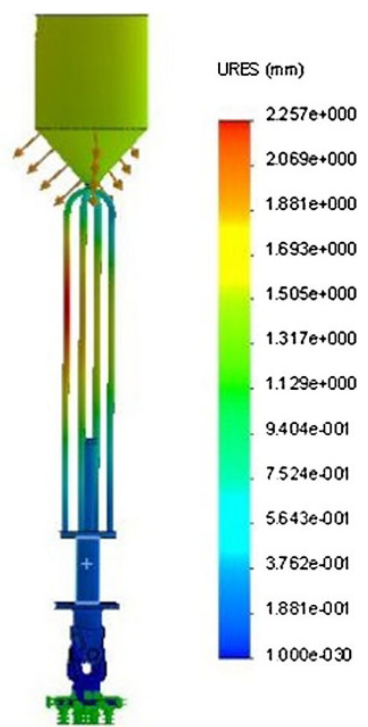

(c)

Fig. 11 Displacement field for retracted position of the hydraulic cylinder piston rod considering partially submerged buoys with radius $100 \mathrm{~mm}$ : a spherical, b cylindrical and $\mathbf{c}$ tulip

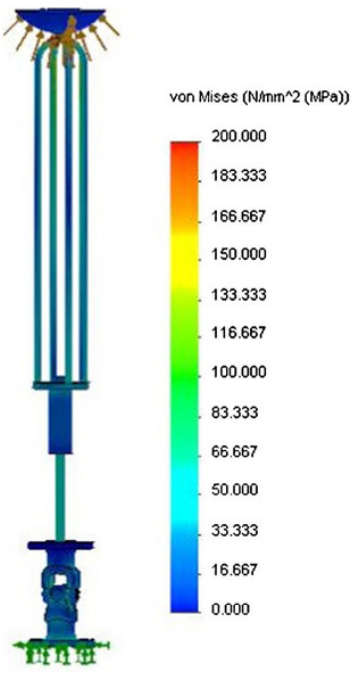

(a)

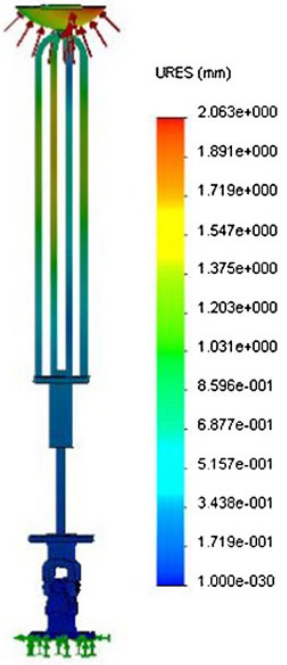

(b)

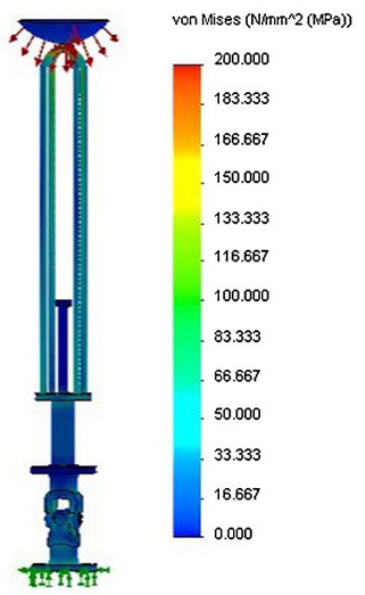

(c)

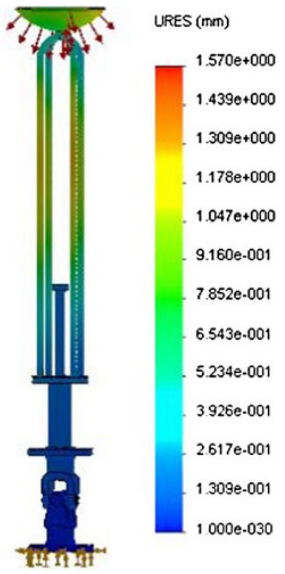

(d)

Fig. 12 Von Mises Stress and displacement fields for the spherical buoy at the surface with radius 100 mm considering: a, b retracted position of the hydraulic cylinder piston rod and $\mathbf{c}, \mathbf{d}$ advanced position of the hydraulic cylinder piston rod

submitted to simulated wave forces. Through the use of a commercial finite element code it was assessed the influence of buoy geometry and dimensions, as well as submerged conditions and extreme stroke positions of the hydraulic cylinder piston rod.

Finite element analysis results demonstrate that, for the load level, sizing WEC components and materials, the spherical buoy geometry presents the lower values for stress concentrations and induces the lowest displacements, leading to the best WEC structural behaviour.
It was also demonstrated that partially submerged buoy corresponds to the critical condition. This is due to the highest values of stresses and displacements reached. In addition, the increase of the buoy dimensions requires the resizing of the WEC components or the selection of a material with greater yield strength to avoid plastic deformation.

The load value computed from the WEC dynamic model equations was very low. As a result, regardless of the hydraulic cylinder piston rod position, buoy geometry and dimensions as well as submerged conditions, no 


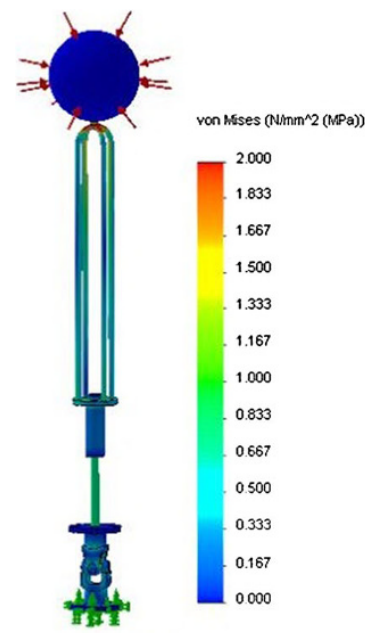

(a)

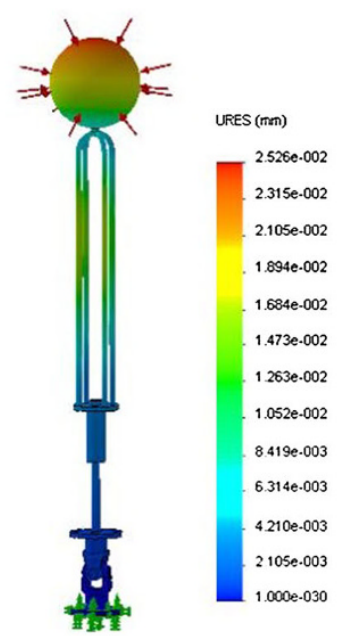

(b)

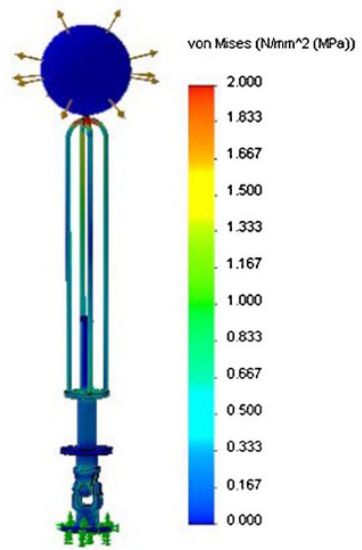

(c)

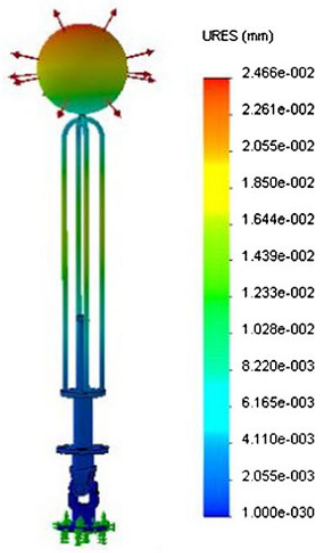

(d)

Fig. 13 Von Mises Stress and displacement fields for the totally submerged spherical buoy with radius 100 mm considering: a, b retracted position of the hydraulic cylinder piston rod and $\mathbf{c}, \mathbf{d}$ advanced position of the hydraulic cylinder piston rod

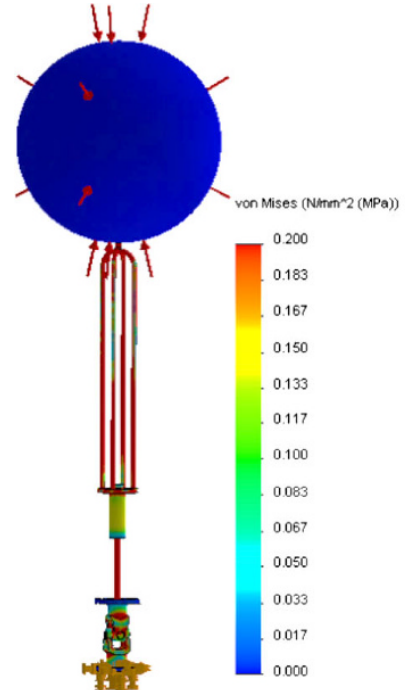

(a)

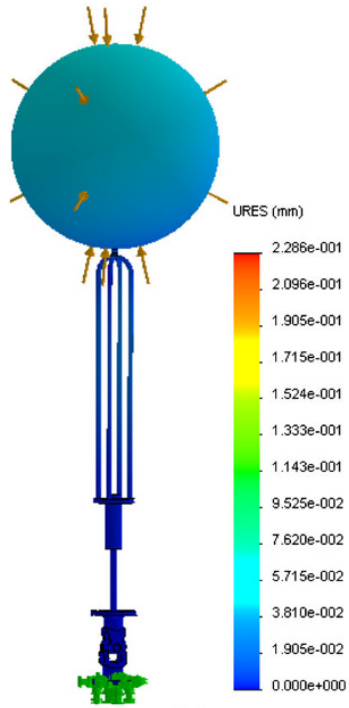

(b)

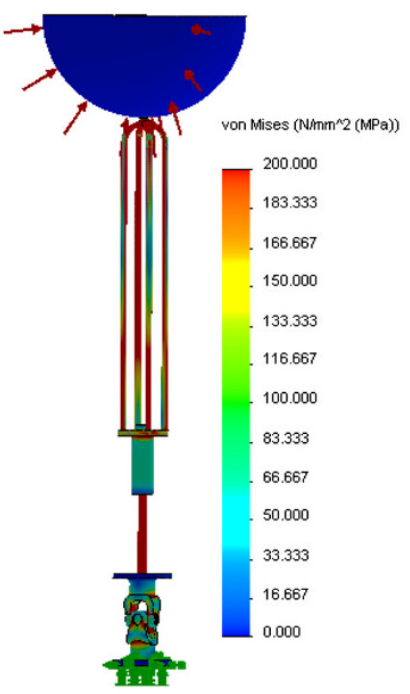

(c)

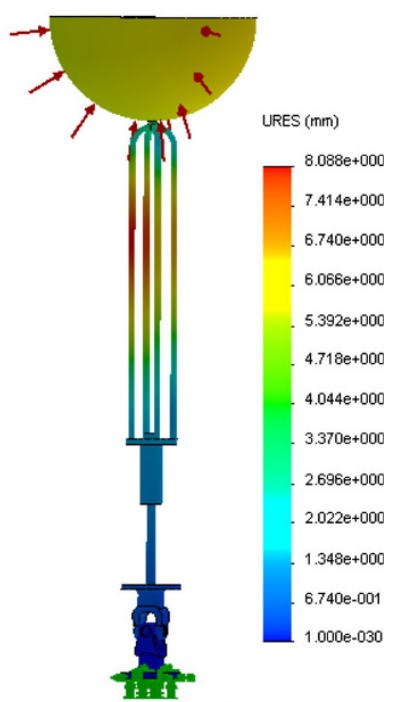

(d)

Fig. 14 Von Mises Stress and displacement fields for: a, b totally submerged and $\mathbf{c}$, $\mathbf{d}$ partially submerged spherical buoy with radius $200 \mathrm{~mm}$ considering the advanced position of the hydraulic cylinder piston rod

conclusions about the mechanical behaviour of the WEC are drawn. This is due to the extremely lower stress and displacement values obtained for the considered dimensions of the WEC components. Therefore, a load with a high magnitude was required. This drawback could be avoided if real irregular waves were taken into account instead of regular periodic waves assumed here. The fact that the WEC has currently a very small scale, thus small dimensions of its components, may also contribute to this scenario. The WEC dynamic and finite element models need to be developed and improved. Some work is required to define reasonable load levels that WEC is submitted to.
Aspects like the structural modification of the original WEC design and sizing must be explored and optimised. These issues will be the target of future work.

Open Access This article is distributed under the terms of the Creative Commons Attribution License which permits any use, distribution, and reproduction in any medium, provided the original author(s) and the source are credited.

\section{References}

1. Valério, D., Beirão, P., Sá da Costa, J.: Optimisation of wave energy extraction with the Archimedes Wave Swing. Ocean Eng. 34(17), 2330-2344 (2007). doi:10.1016/j.oceaneng.2007.05.009 
2. Pelc, R., Fujita, R.: Renewable energy from the ocean. Mar. Policy 26(6), 471-479 (2002). doi:10.1016/S0308-597X(02)00045-3

3. Leijon, M., Danielsson, O., Eriksson, M., Thorburn, K., Bernhoff, H., Isberg, J., Sundberg, J., Ivanova, I., Sjöstedt, E., Agren, O., Karlsson, K., Wolfbrandt, A.: An electrical approach to wave energy conversion. Renew. Energy 31, 1309-1319 (2006). doi:10.1016/j.renene.2005.07.009

4. Boström, C., Lejerskog, E., Stålberg, M., Thorburn, K., Leijon, M.: Experimental results of rectification and filtration from an offshore wave energy system. Renew. Energy. 34, 1381-1387 (2008). doi:10.1016/j.renene.2008.09.010

5. Beirão, P., Malça, C.: Hydraulic power take-off prototype for a wave energy converter. In: Proceedings of the 4th International Congress of Energy and Environment Engineering and Management, Mérida, Spain, 25-27 May 2011

6. Falnes, J.: A review of wave-energy extraction. Mar. Struct. 20(4), 185-201 (2007). doi:10.1016/j.marstruc.2007.09.001

7. Henderson, R.: Design, simulation, and testing of a novel hydraulic power take-off system for the Pelamis wave energy converter. Renew. Energy 31(2), 271-283 (2006). doi:10.1016/j. renene.2005.08.021

8. Spooner, E., Mueller, M.A.: Comparative study of linear generators and hydraulic systems for wave energy conversion ETSU V/06/00189/REP DTI/Pub URN 01/783. University of Durham School of Engineering. http://www.tridentenergy.co.uk/pdf/ DTI\%20Report.pdf (2007). Accessed 25 Sept 2013

9. Falcão, A.: Wave energy utilization: a review of the technologies. Renew. Sustain. Energy Rev. 14(3), 899-918 (2010). doi:10. 1016/j.rser.2009.11.003
10. Bacelli, G., Gilloteaux, J.C., Ringwood, J.: State space model of a hydraulic power take off unit for wave energy conversion employing bondgraphs. In: Proceedings of World Renewable Energy Conference, Glasgow, 19-25 July 2008

11. Falnes, J.: Ocean Waves and Oscillating Systems. Cambridge University Press, Cambridge (2004)

12. Sarlak, H., Seif, M., Abbaspour, M.: Experimental investigation of offshore wave buoy performance. J. Mar. Eng. 6, 1-11 (2006)

13. Biesheuvel, A., Spoelstra, S.: The added mass coefficient of a dispersion of spherical gas bubbles in liquid. Int. J. Multiphase Flow 15(6), 911-924 (1989). doi:10.1016/0301-9322(89)90020-7

14. Vu, K., Chenu, B., Thiagarajan, K.: Hydrodynamic damping due to porous plates. In: Proceedings of the WSEAS International Conference on Fluid Mechanics, Corfu, 17-19 August 2004

15. Demirbilek, Z., Vincent, C.: Water Wave Mechanics Coastal Engineering Manual (EM 1110-2-1100). U.S. Army Corps of Engineers, USA (2002)

16. Finnegan, W., Meere, M., Goggins, J.: The wave excitation forces on a truncated vertical cylinder in water of infinite depth. J. Fluids Struct. 40, 201-213 (2013). doi:10.1016/j.jfluidstructs.2013.04. 007

17. Eriksson, M., Isberg, J., Leijon, M.: Hydrodynamic modelling of a direct drive wave energy converter Int. J. Eng. Sci. 43, 1377-1387 (2005). doi:10.1016/j.ijengsci.2005.05.014

18. Beirão, P., Malça, C.: Dynamic simulation in the time domain of a wave energy converter. In: Proceedings of the International Conference on Engineering-ICEUBI 2013, Covilhã, Portugal, 27-29 November 2013 